\title{
Structural and Geometrical Vegetation Filtering - Case Study on Mining Area Point Cloud Acquired by UAV Lidar
}

\author{
Jaroslav BRAUN ${ }^{1 *}$, Hana BRAUNOVÁ2 ${ }^{2}$ Tomáš SUK ${ }^{3}$, Ondřej MICHAL ${ }^{4}$, \\ Patrik PEŤOVSK ${ }^{5}$ and Ivan KURIC $C^{6,7}$
}

\begin{abstract}
Authors' affiliations and addresses:
${ }^{1}$ Department of Special Geodesy, Faculty of Civil Engineering, Czech Technical University in Prague,

Thákurova 7, 16636 Prague 6, Czech Republic

e-mail: jaroslav.braun@fsv.cvut.cz

${ }^{2}$ Department of Special Geodesy, Faculty of Civil Engineering, Czech Technical University in Prague, Thákurova 7, 16636 Prague 6, Czech Republic e-mail: hana.braunova@fsv.cvut.cz

${ }^{3}$ Department of Special Geodesy, Faculty of Civil Engineering, Czech Technical University in Prague, Thákurova 7, 16636 Prague 6, Czech Republic e-mail: tomas.suk@fsv.cvut.cz

${ }^{4}$ Department of Special Geodesy, Faculty of Civil Engineering, Czech Technical University in Prague, Thákurova 7, 16636 Prague 6, Czech Republic e-mail: ondrej.michal@fsv.cvut.cz
\end{abstract}

${ }^{5}$ Ústav geodézie, kartografie a geografických informačných systémov, FBERG TUKE, Park Komenského 19, 04200

Košice

e-mail: patrik.petovsky@tuke.sk

${ }^{6}$ Department of Automation and Production Systems, Faculty of Mechanical Engineering, University of Žilina, Univerzitná 8215/1, 01026 Žilina, Slovakia

e-mail: ivan.kuric@fstroj.uniza.sk

${ }^{7}$ University of Bielsko-Biala, Faculty of Mechanical Engineering and Computer Science Willowa 2, 43-309 Bielsko-Biala, Poland

\section{*Correspondence:}

Jaroslav Braun, Department of Special Geodesy, Faculty of Civil Engineering, Czech Technical University in Prague, Thákurova 7, 16636 Prague 6, Czech Republic tel.: +420-22435-4780

e-mail: jaroslav.braun@fsv.cvut.cz

\section{Funding information:}

Grant Agency of CTU in Prague.

SGS21/053/OHK1/1T/1

\section{Acknowledgement:}

This research was funded by the Grant Agency of CTU in Prague - grant number SGS21/053/OHK1/1T/11

"Optimization of acquisition and processing of 3D data for purpose of engineering surveying, geodesy in underground spaces and 3D scanning".

\section{How to cite this article:}

Braun, J., Braunová, H., Suk, T., Michal, O., Petovský, P. and Kuric, I.. (2021). Structural and Geometrical Vegetation Filtering - Case Study on Mining Area Point Cloud Acquired by UAV Lidar. Acta Montanistica Slovaca. Volume 26 (4) 661-674

DOI:

https://doi.org/10.46544/AMS.v26i4.06

\begin{abstract}
Filtering vegetation in point clouds is one of the basic steps in processing the products of bulk data collection. Commonly used filtering methods have been developed for large areas, usually scanned from an aircraft at high altitude, where the point clouds are very poorly detailed, and the terrain is essentially flat. Nowadays, point clouds are generated not only by aerial and ground scanning but mainly by photogrammetry from UAVs and, more recently, by scanners mounted on UAVs. Various objects are measured, including anthropogenic objects, rugged areas with large elevations, rocks, pits, buildings, etc. Therefore, the aim of filtering is no longer to remove everything from the cloud except the ground surface but to remove vegetation as such and some unnecessary objects. In this task, the use of structure filters, which classify points based on the surrounding of each point in terms of its structure, seems to be advantageous.

Since many different filtering algorithms have been developed and their behaviour is controlled by the parameters chosen, it is necessary to test suitable filters and their settings for each type of area.

In this paper, selected freely available filtering methods based on a geometric approach are tested as a comparison to the CANUPO-based structure filter, which is the main object.

Testing of ground filtering procedures on real data acquired by the UAV 3D scanner DJI L1 corresponding to the nature of the mining area was performed. Test results were evaluated by type I error, type II error, and total error, where type I error represents incorrectly unremoved points, type II error represents incorrectly removed points, and total error represents the sum of type I error and type II error. The tested geometric filters CSF, PMF and SMRF showed an overall error of about $7.5 \%$ in the best case, of which error type I constitutes a significantly larger part (about 6\%) than error type II (about 2\%). In contrast, the tested CANUPO structural filter in basic use achieved up to $5.2 \%$ total error, using a defined probability bound of up to $4.1 \%$. The distribution of errors of type I and type II is almost even here. The specific probability set here has a relatively small effect on the result, at $0.1 \%$ of the total error.

Some additional insights into the design and use of filters emerged from the testing. Geometric filters are significantly faster, but CANUPO is significantly more reliable in terms of removing vegetation as points having a character of noise. In particular, the maximum radius used and the total number of filters must be considered when creating a filtering (training) prescription.
\end{abstract}

\section{Keywords}

Point cloud, ground filtering, geometric filtering, structural filtering 


\section{Introduction}

Spatial data collection methods (photogrammetry and laser scanning) are currently gaining ground in common practice in geodesy (Teppati et al., 2020), construction (Vacca et al., 2017), (Kovanič et al., 2021), (Feroz and Abu Dabous, 2021), energy (Tan et al., 2021), (Dihkan and Mus, 2021), ecology (Klouček et al. 2019), (Komárek et al., 2018), archaeology (Šedina et al. 2019), coast monitoring (Jaud et al. 2020), (Lin et al., 2019), natural hazards (Žabota and Kobal, 2021), (Blišt'an et al., 2020), (Kovanič et al., 2020) or calculation of groundwork volumes (Urban et al., 2020), (Blišt'an et al. 2020), (Kovanič et al., 2021).

With the rapid development of UAV technology and digital photogrammetry, the Structure from Motion (SfM) method is usually used today, which makes it possible to obtain a point cloud under very good economic conditions (Urban et al., 2019), (Štroner et al., 2019). However, for the correct processing of the photogrammetric method, the correct placement of ground control points (GCP), a suitable flight strategy (Štroner et al., 2020), (Štroner et al., 2021) and also the correct computational algorithm are necessary. The accuracy and usability of the resulting point cloud are further dependent on the ground sample distance (GSD) of the images and the density of the resulting point cloud (Urban et al., 2018), (Moudrý et al., 2019).

In contrast, the laser scanning method is more expensive, but the result is directly a point cloud. The laser scanning method was first applied by ground instruments (Pukanská et al., 2020), (Kovanič et al., 2020), (Křemen, 2020), or the laser scanner was placed in an aircraft (Siwiec, 2018). In recent years, the placement of a laser scanner on the UAV platform with a fixed-wing or rotary-wing (Hu et al., 2020), (Torresan et al., 2018) and on other flying platforms, such as the airship (Koska et al. 2017), (Urban et al., 2016), (Jon et al., 2013), has become increasingly popular. The accuracy of laser scanners is usually specified by the manufacturer and can be tested using special reflective control points or a sufficiently accurate point cloud obtained by another method (Štroner et al., 2021). It seems very advantageous today to use a combination of both methods (Koska and Křemen, 2013), which complement each other. The advantages and disadvantages of both methods are described, for example, in the publication (Shaw et al., 2019).

This article deals with the mass collection of data in mining areas that are specific to very rugged terrain, as can be seen from the articles (Kovanič, 2013), (Urban et al., 2016), (Ren et al., 2019). For the correct interpretation of the surface, it is necessary to remove unwanted elements such as parked vehicles, buildings, structures, and especially vegetation.

Many vegetation filtration procedures are known and have been published in recent years (Meng et al., 2009), (Rashidi and Rastiveis, 2017), (Shi et al., 2018), (Li et al., 2020). Some are included in commercial software or are provided as free or open-source software (Tinhkam et al., 2011), (Montealegre et al., 2015), (Yilmaz et al., 2018). Common to many of these filters is that they were developed for Lidar data taken from an aircraft where the carrier is relatively far from the earth's surface (Polat and Uysal, 2015), (Wei et al., 2017), (Kumar et al., 2016), Susaki, 2012), but filters designed for ground-based laser scanning (Brodu and Lague, 2012) can be found. A very interesting alternative is the use of filters based on PCA algorithms (Cheng et al., 2021). However, various geometric filters are commonly used, which have also been tested many times in (Moudrý et al., 2020), (Klápště et al., 2020), (Cai et al., 2019), (Silva et al., 2018).

With the development of UAVs, it is typical for both photogrammetry and laser scanning methods that the carrier is placed relatively close to the surface, and the point cloud density makes it possible to record even very rugged surfaces realistically. As shown in (Štroner et al., 2021), the use of geometric filters in rugged areas is not suitable, and a better result was achieved with a structural filter based on the CANUPO tool, which allows you to train your own filter. Its use for vegetation filtering has not yet been explored, especially as regards the process of creating a filter definition. The aim of the article is to test the effectiveness of various variants of trained CANUPO filters on typical mining area data obtained by the UAV scanning system and to compare their success with the results of selected geometric filters.

\section{Material and Methods}

\section{Testing data}

The test data was acquired by a DJI Matrice 300 UAV with a DJI Zenmuse L1 scanning system. The measurements were performed in June 2021 under full vegetation cover in the vicinity of the village of Sedlice in the Košice Region, Slovak Republic. The flight height was $100 \mathrm{~m}$ above the lower level of the area, a single grid scheme of the raid was used, the onboard GNSS RTK receiver was connected to the SKPOS network of permanent reference stations. This information is presented here for the overall picture; it is not significant from the testing point of view. 


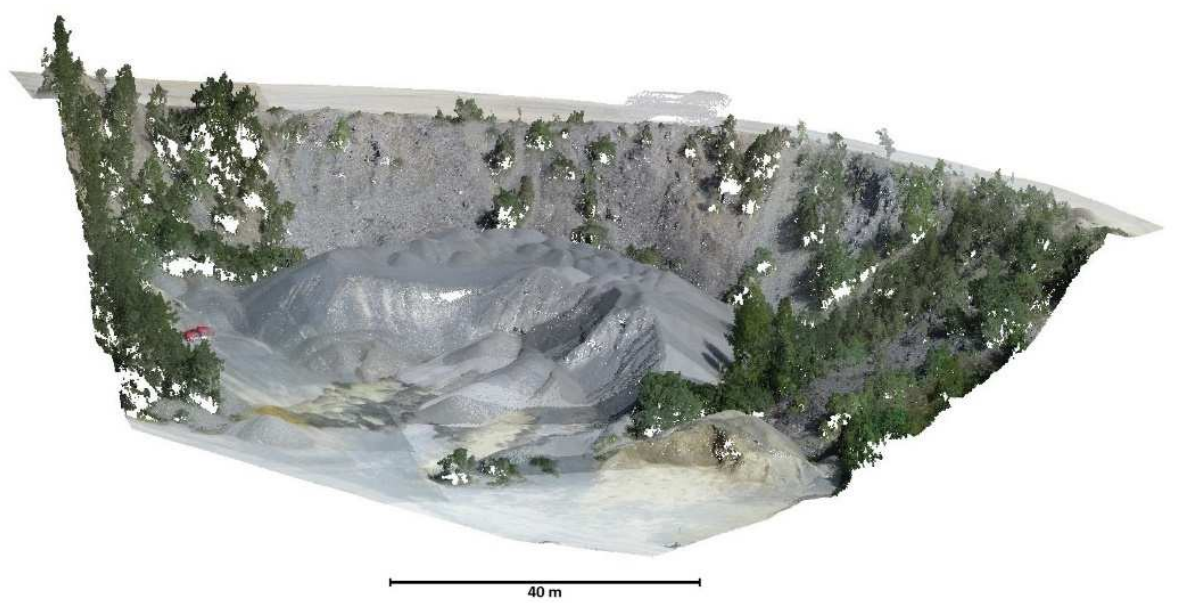

a)

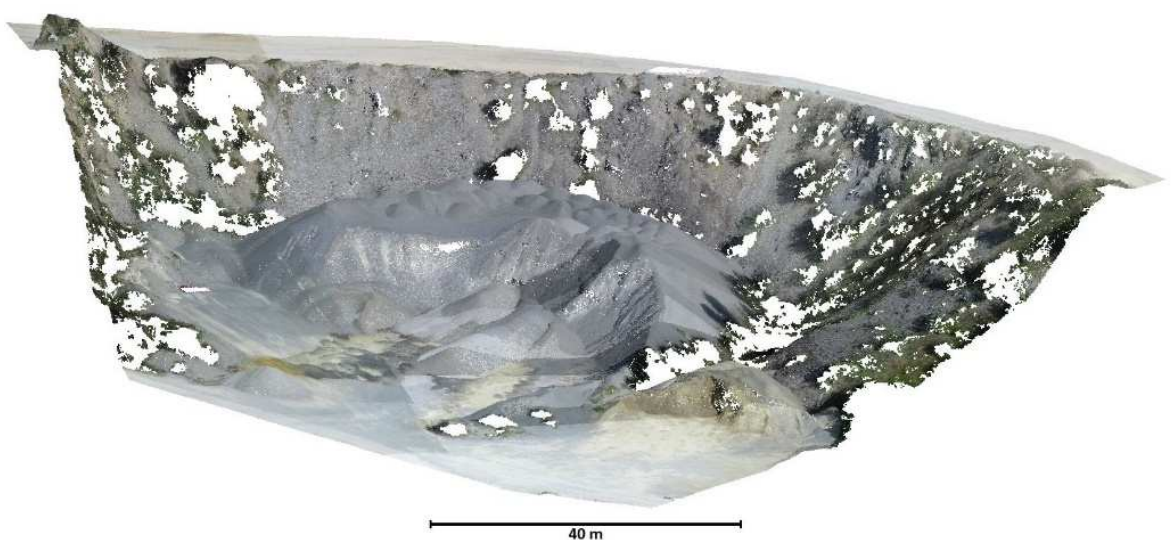

b)

Fig. 1. Test data - point cloud used for testing - a) cloud with vegetation b) cloud manually de-vegetated

The scanned data was decimated to a density of about 100 points $/ \mathrm{m}^{2}$, the cloud used for testing contained 1457259 points, the acreage of the area was $9955 \mathrm{~m}^{2}$, the elevation between the lowest and highest point of the terrain was $25 \mathrm{~m}$. The data were selected because of the presence of both rugged surface with a high slope, and more or less dense vegetation in the form of both thickets and trees. In order to reliably test the success of vegetation removal, the test plume (see Fig. 1a) was manually cleared to obtain a comparison plume (see Fig. 1b). To illustrate the nature of the data, Fig. 1c shows the problematic part of the cloud with dense vegetation of different heights, then the heap in the background (grey).

\section{Tested ground filtering algorithms}

For testing, ground filtering algorithms implemented in freely available software packages were used. Specifically, CSF (Cloth Simulation Filter), PMF (Progressive Morphological Filter) and SMRF (Simple Morphological Filter) were used, and their principle is described in detail in (Zhang et al., 2003) (Pingel et al., 2013) (Zhang et al., 2003). These are filters based on the primary generation of a surface approximation, which is used to filter point clouds based on the point-to-approximation surface distance subsequently. The PMF and SMRF filters were used in the implementation in the PDAL software package (http://pdal.io), and the CSF in the CloudCompare version 2.12 software implementation.

CANUPO (described in detail in (Brodu and Lague, 2012)) was used as a structural filter, whose outstanding feature is the possibility of creating a custom filter for specific data. Two separate training clouds need to be created to create the filter - one representing the vegetation class, the other representing the surface class. The calculation is based on principal component analysis (PCA) with different radii of spherical neighbourhoods and subsequent statistical processing. Thus, when creating a custom filter, in addition to the custom type clouds, it is necessary to define how many and how large (defined by radius) neighbourhoods (dimensions) will be used. This is not a simple choice; in general, a higher number of dimensions means better quality results but also longer processing time. According to the conclusions of (Štroner et al., 2021), this filter is very useful in distinguishing scattered point cloud parts from points forming "smooth and continuous" surface areas.

Each filter used can be used with different settings (CSF, PMF, SMRF with numerical constants defining the filter behaviour; for CANUPO, it is the different number and size of spherical surroundings used for evaluation). 
However, the optimal setting is not generally known. Therefore, determining the best setting is also part of the testing. The tested settings are listed in Table 1; for settings not listed, the default ones were used.

Table 1. Tested filter's parameters variants

\begin{tabular}{|c|c|c|}
\hline Method & Parameters & Values \\
\hline PMF & $\begin{array}{c}\text { Cell size }[\mathrm{m}] \\
\text { Initial distance }[\mathrm{m}] \\
\text { Max distance }[\mathrm{m}] \\
\text { Max window size }[\mathrm{m}] \\
\text { Slope } \\
\text { Exponential }\end{array}$ & $\begin{array}{c}0.1 ; 0.3 ; 0.5 ; 1.0 ; 2.0 \\
0.10 ; 0.5 ; 1.0 \\
0.1 ; 0.2 ; 0.5 ; 1.0 ; 2.5 \\
0.2 ; 0.5 ; 1.0 ; 5.0 ; 10.0 \\
1.0 ; 3.0 ; 5.0 ; 10.0 ; 20 \\
\text { Yes }\end{array}$ \\
\hline SMRF & $\begin{array}{l}\text { Cell }[\mathrm{m}] \\
\text { Scalar }[\mathrm{m}] \\
\quad \text { Slope } \\
\text { Threshold }[\mathrm{m}] \\
\text { Window }[\mathrm{m}]\end{array}$ & $\begin{array}{c}0.1 ; 0.3 ; 0.5 ; 1.0 ; 2.0 \\
0.5 ; 1.0 ; 1.25 ; 2.5 ; 5.0 \\
3.0 ; 5.0 ; 10.0 ; 20.0 \\
0.1 ; 0.2 ; 0.3 ; 0.4 ; 0.5 ; 0.75 ; 1.0 ; 2.0 ; 3.0 ; 5.0 \\
0.5 ; 1.0 ; 2.0 ; 3.0 ; 5.0 ; 10.0\end{array}$ \\
\hline CSF & $\begin{array}{l}\text { Cloth resolution }[\mathrm{m}] \\
\text { Classification threshold }[\mathrm{m}] \\
\text { Scene } \\
\text { Slope processing } \\
\text { Max iterations }\end{array}$ & $\begin{array}{c}0.05 ; 0.1 ; 0.2 ; 0.3 ; 0.4 ; 0.5 ; 0.75 ; 1.0 ; 2.0 ; 3.0 ; 5.0 \\
0.05 ; 0.1 ; 0.2 ; 0.3 ; 0.4 ; 0.5 ; 0.75 ; 1.0 ; 2.0 ; 3.0 ; 5.0 \\
\text { Steep slope } \\
\text { Yes } \\
500\end{array}$ \\
\hline
\end{tabular}

CANUPO filtering was tested on the same sample data with different sizes and numbers of neighbourhoods listed in Table 2.

Table 2. CANUPO filter's parametres variants

\begin{tabular}{|c|c|}
\hline Table 2. CANUPO filter's parametres variants \\
\hline Parameter & Value \\
\hline Minimum radius $[\mathrm{m}]$ & $0.1 ; 0.2 ; 0.3 ; 0.5 ; 1.0$ \\
\hline Step between adjacent radii $[\mathrm{m}]$ & $0.1 ; 0.2 ; 0.3 ; 0.5 ; 1.0$ \\
\hline Maximum radius [m] & $1.0 ; 3.0 ; 5.0 ; 10.0$ \\
\hline Probability [\%] & none; $99 ; 95 ; 90 ; 85 ; 80 ; 75$ \\
\hline
\end{tabular}

For both geometric filters (PMF, SMRF, CSF) and structural filters (CANUPO), all combinations of these parameters were tested. CANUPO also provides, in addition to the intended classification, the reliability (probability) of the classification and can be classified in such a way that a point is assigned to a given class only if the reliability of its identification reaches at least a chosen threshold. This method of evaluation has been tested with the result that not classified points in any class are considered to be surface points.

\section{Filter quality evaluation}

Testing the efficiency of a particular filter was always carried out using the same procedure:

1. Applying a specific filtering procedure to the test data (data_orig) with a specific setting (data_filter is created).

2. Determining the first type of error (Error type I) by comparing the data_filter with the reference (manually cleaned, data_etal) data in CloudCompare.

3. Determine the second type of error (Error type II) by comparing the data_filter with the reference (manually cleaned, data_etal) data in CloudCompare.

4. Calculation of evaluation criteria.

5. Repeat steps 1-4 for all filters and variations tested.

The error type I is determined by calculating the distance between data_filter and data_etal (cloud to cloud distance function in CloudCompare). Points that are further away than the selected value of $0.01 \mathrm{~m}$ (chosen due to the data resolution of $0.1 \mathrm{~m}$ ) remained in the cloud, although they should have been discarded, are then evaluated as an error type I.

An error type II is determined by the same procedure; only the comparison is made in reverse order (data_etal and data_filter). Points that are further away than the selected value $(0.01 \mathrm{~m})$ have been discarded, although they should have remained there, are evaluated as an error type II. A single summary criterion was then determined for the overall evaluation, obtained by simply summing errors type I and II (hereafter referred to as the total error). For each filter, an evaluation was performed for all combinations of parameter settings, and then the combinations that gave the best results in terms of total error (sum of type I and type II errors) were selected. 


\section{Results}

The results of the testing are shown in the following tables. Due to the large amount of data found, the data is divided into results obtained by geometric filters and procedures using CANUPO. To increase the clarity of the presentation of the results, the efficiency is described as a percentage (100\% is the total number of points of the filtered data_orig cloud, 1,457,259 points). The first 5 different results are shown to show how different the results are and whether the detected optimum is flat or sharp because in practical use, it is not possible to check the quality of the result in such an exact way, and the parameters have to be chosen based on experience or guesswork. Since there are many filters setting parameters in some cases, abbreviations (listed below the table) have been used here. For all tables, the abbreviations that E I; E II and TE stand for Error type I, Error type II and Total Error, respectively.

Table 3. Best results achieved by the PMF geometric filter

(CS - cell_size; ID - initial_distance; $M D$ - max_distance; $M W S$ - max_window_size $; S$-slope)

\begin{tabular}{|c|c|c|c|c|c|c|c|}
\hline \multicolumn{9}{|c|}{ Parameters } & \multicolumn{4}{c|}{ Results } \\
\hline CS [m] & ID [m] & MD [m] & MWS [m] & S [m] & E I [\%] & E II [\%] & TE [\%] \\
\hline 1 & 1 & 3 & 5 & 1 & 5.9 & 1.5 & 7.4 \\
\hline 1 & 1 & 1 & 0.2 & 1 & 5.9 & 1.5 & 7.4 \\
\hline 1 & 1 & 1 & 5 & 1 & 5.6 & 2.4 & 8.1 \\
\hline 0.5 & 1 & 1 & 5 & 1 & 5.8 & 2.5 & 8.3 \\
\hline 0.5 & 1 & 3 & 10 & 1 & 6.6 & 1.8 & 8.4 \\
\hline
\end{tabular}

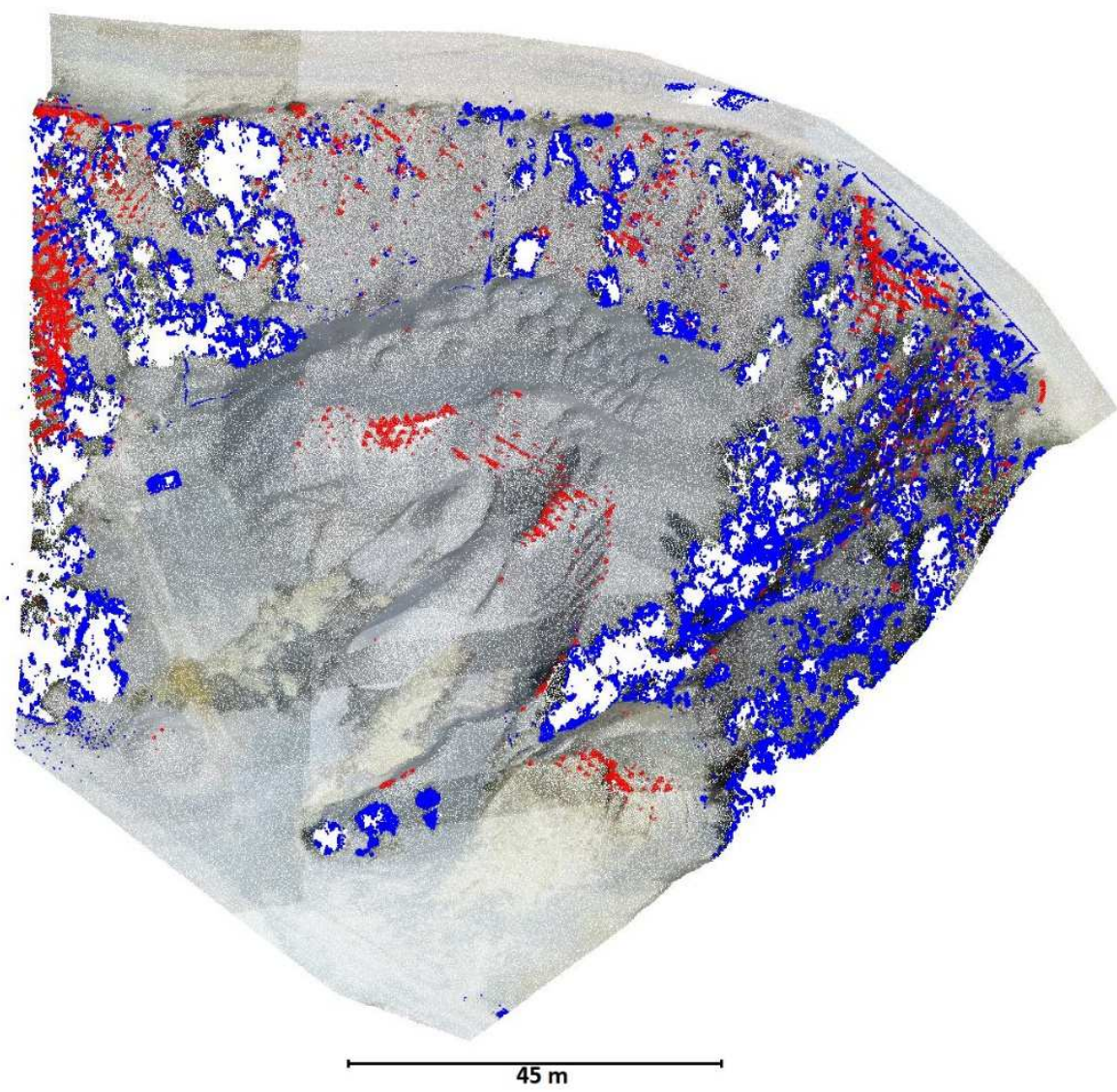

Fig. 2. Quality evaluation of ground filtering - the best PMF variant

Table 3 shows the top 5 results obtained by the PMF along with the settings used, and Fig. 2 shows the correctly evaluated terrain in natural colour, points that should have been removed and were not (error type I) in blue, and points that should not have been removed and were (error type II) in red. It is clear that filtering does not remove low vegetation or vegetation below which the terrain is not covered by points. On the contrary, there were parts of the point cloud removed where there are significant changes in the character of the terrain. This is well evident in the middle part of the image on the tops of the heap; then, there is a very steep area to the top left. The unremoved points are $5.9 \%$, the erroneously removed points are about $1.5 \%$, the total error is then $7.4 \%$ at best. The top 5 results presented differ very little in terms of total error. 
The results of the CSF filter are very similar to the PMF filter in terms of overall error (7.4\%), the Type I and Type II errors are also similarly distributed, and the reported results are consistent. The parameters used are both cloth resolution and a classification threshold of about $0.3 \mathrm{~m}$ (three times the resolution of the filtered cloud itself).

Table 4. Best results achieved by the CSF geometric filter
\begin{tabular}{|c|c|c|c|c|}
\hline \multicolumn{3}{|c|}{ Results } \\
\hline Parameters & Class threshold [m] & E I [\%] & E II [\%] & TE [\%] \\
\hline Cloth resolution [m] & 0.3 & 5.4 & 2.0 & 7.4 \\
\hline 0.3 & 0.2 & 4.5 & 2.9 & 7.4 \\
\hline 0.3 & 0.4 & 6.0 & 1.5 & 7.5 \\
\hline 0.3 & 0.2 & 5.7 & 1.9 & 7.5 \\
\hline 0.2 & 0.3 & 6.5 & 1.1 & 7.6 \\
\hline 0.2 & & & & \\
\hline
\end{tabular}

Compared to the PMF results, the CSF (see Fig. 3) adapts better to the rugged terrain (as seen again in the middle part), but it performs worse in the left part, which is steep. It also removes extraneous features better (for instance, the car in the middle left).

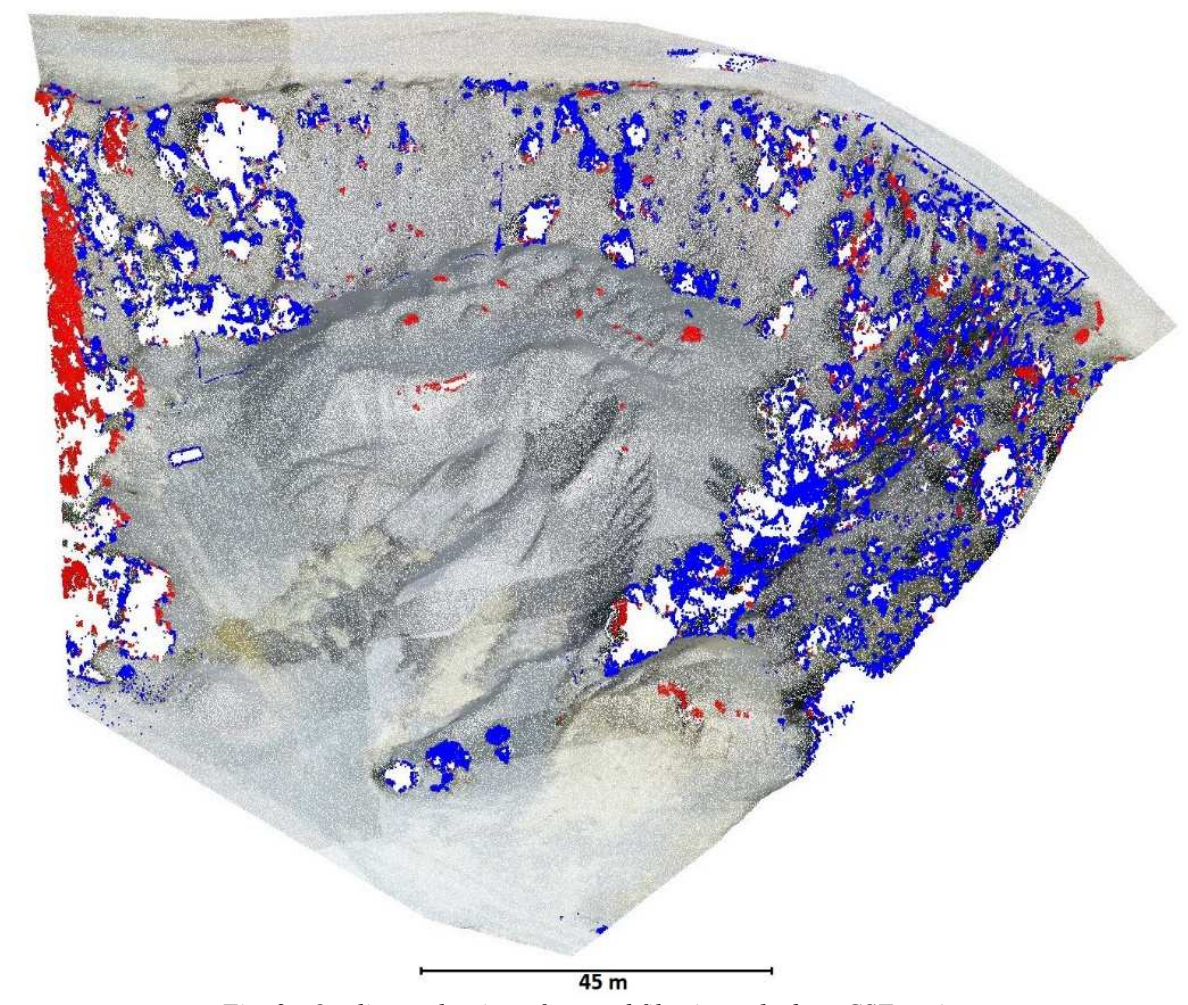

Fig. 3. Quality evaluation of ground filtering - the best CSF variant

The SMRF filter (see Fig. 4) achieved an overall error similar to the other geometric filters (7.3\%), the error distribution is significantly more in favour of the first kind of error $(6.7 \%)$, whereas the second kind of error is significantly smaller here $(0.7 \%)$. The filter adapts quite well to steep terrain (top left in the figure). However, where the nature of the terrain changes significantly, there is an erroneous removal of terrain points throughout the area.

Overall, the results of the geometric filters can be said to achieve the same results in a given rugged region, although each of them has different evaluation errors, which is probably due to the geometric nature of the process. 
Table 5. Best results achieved by the SMRF geometric filter

(Cell-Ce; Scalar-Sc; Slope - Sl; Threshold-Tr; Window - Wi)

\begin{tabular}{|c|c|c|c|c|c|c|c|}
\hline \multicolumn{9}{|c|}{ Parameters } & \multicolumn{5}{c|}{ Results } \\
\hline $\mathrm{Ce}[\mathrm{m}]$ & $\mathrm{Sc}[\mathrm{m}]$ & $\mathrm{S} 1[\mathrm{~m}]$ & $\mathrm{Tr}[\mathrm{m}]$ & $\mathrm{Wi}[\mathrm{m}]$ & $\mathrm{E} \mathrm{I} \mathrm{[ \% ]}$ & E II [\%] & TE [\%] \\
\hline 1 & 1 & 3 & 0.3 & 1 & 6.7 & 0.7 & 7.3 \\
\hline 1 & 0.5 & 3 & 0.5 & 1 & 5.7 & 1.7 & 7.4 \\
\hline 1 & 0.5 & 5 & 0.5 & 1 & 5.9 & 1.7 & 7.6 \\
\hline 1 & 1 & 5 & 0.3 & 1 & 6.9 & 0.7 & 7.6 \\
\hline 1 & 0.5 & 10 & 0.5 & 1 & 5.9 & 1.7 & 7.6 \\
\hline
\end{tabular}

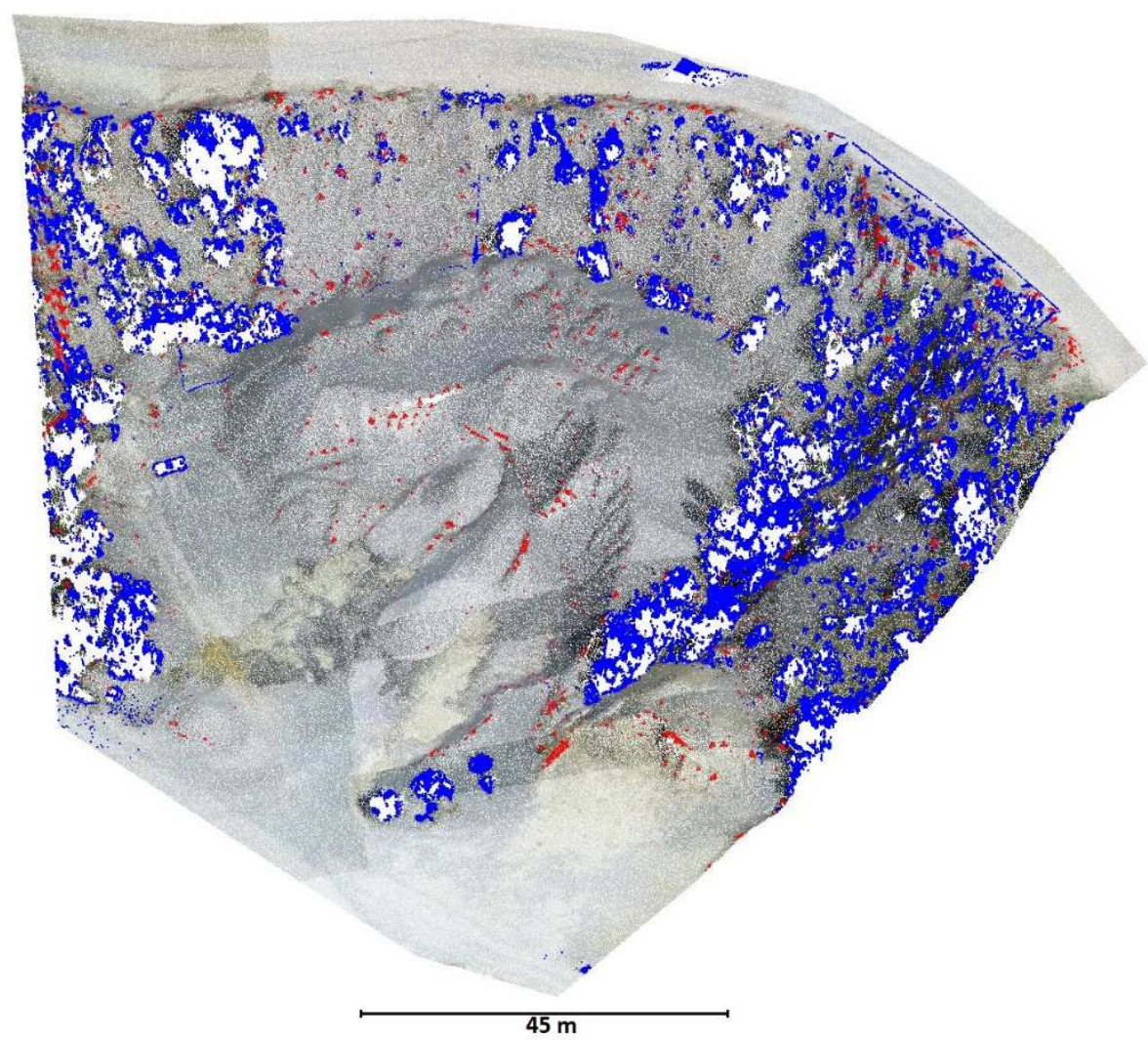

Fig. 4. Quality evaluation of ground filtering - the best SMRF variant

CANUPO filtration works on a different principle. As can be seen in the results, it reliably distinguishes points on surfaces from scattered points characterizing vegetation. CANUPO filtering without probability achieves an overall performance of $5.2 \%$, i.e. about $2 \%$ better than geometric filters, with an error of the first kind of about $2.1 \%$ and an error of the second kind of $3.1 \%$. Compared to geometric filters, this means that it removes rather than erroneously retains more points. The erroneously removed points are mainly on the edges of solid surfaces. Using the CANUPO filter with the probability option (75\% - up to 99\%) improves the overall error by an additional $1 \%$, where the error of the first kind is approximately the same as the error of the second kind (both $2 \%$ ). The differences between the results using probability are minimal; $0.1 \%$ cannot be taken as a significant difference this corresponds to 1.4 thousand points. Since the results are very similar between the different variants of the CANUPO filter with probability selection, only the best results of each variant are reported directly in the text (Table 6).

Table 6. Best results achieved by the CANUPO structural filter

(Minimum radius - Mi; Step between radii - St; Maximum radius - Ma.)

\begin{tabular}{|c|c|c|c|c|c|c|}
\hline Filter & \multicolumn{3}{|c|}{ Parameters } & \multicolumn{3}{c|}{ Results } \\
\hline & Mi [m] & St [m] & Ma [m] & E I [\%] & E II [\%] & TE [\%] \\
\hline CANUPO & 0.3 & 0.1 & 10 & 2.1 & 3.1 & 5.2 \\
\hline CANUPO 75\% & 0.3 & 0.1 & 10 & 2.0 & 2.4 & 4.4 \\
\hline CANUPO 80\% & 0.1 & 0.1 & 10 & 2.0 & 2.1 & 4.1 \\
\hline CANUPO 85\% & 0.3 & 0.1 & 10 & 2.0 & 2.3 & 4.3 \\
\hline CANUPO 90\% & 0.3 & 0.1 & 10 & 2.0 & 2.2 & 4.2 \\
\hline CANUPO 95\% & 0.3 & 0.1 & 10 & 2.2 & 2.0 & 4.1 \\
\hline CANUPO 99\% & 0.1 & 0.1 & 10 & 2.0 & 2.1 & 4.1 \\
\hline
\end{tabular}




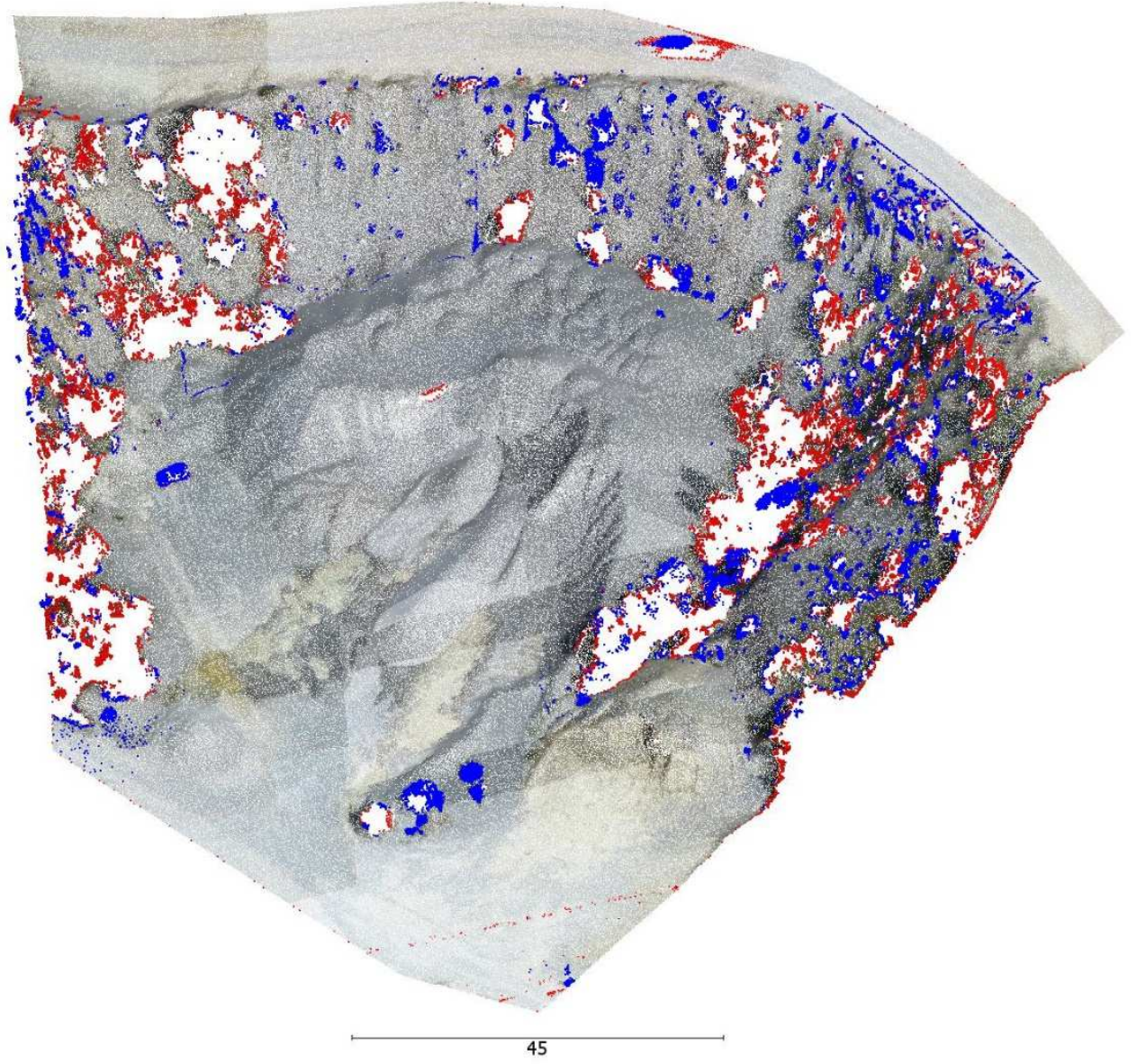

Fig. 5. Quality evaluation of ground filtering - the best CANUPO variant (95\% probability)

One side of Table 7 are the most efficient results of the top five achieved by the Canupo structural filter evaluation is the resulting filtering error; the other side is the computational complexity. Especially in the case of CANUPO filtering, it is necessary to consider how to set up the filter generation. The number of radii determines the difficulty of the calculation, and it is, therefore, advisable to choose a larger step in terms of filtering speed. The maximum number of 100 radii is for a filter with a minimum of $0.1 \mathrm{~m}$, a step of $0.1 \mathrm{~m}$ and a maximum of 10 m. As can be seen from Table 7, practically the same results can be achieved with half the number of radii.

Table 7. The most efficient results of the top five achieved by the Canupo structural filter (Minimum radius - Mi; step between radii - St; Maximum radius - Ma.)

\begin{tabular}{|c|c|c|c|c|c|c|c|}
\hline \multirow[t]{2}{*}{ Filter } & \multicolumn{3}{|c|}{ Parameters } & \multirow{2}{*}{$\begin{array}{c}\text { Radii } \\
\text { number }\end{array}$} & \multicolumn{3}{|c|}{ Results } \\
\hline & $\mathrm{Mi}[\mathrm{m}]$ & St [m] & $\mathrm{Ma}[\mathrm{m}]$ & & E I [\%] & E II [\%] & TE [\%] \\
\hline CANUPO & 0.3 & 0.2 & 10 & 49 & 2.1 & 3.1 & 5.2 \\
\hline CANUPO 75\% & 0.3 & 0.2 & 10 & 49 & 2.0 & 2.4 & 4.4 \\
\hline CANUPO 80\% & 0.1 & 0.2 & 10 & 50 & 2.5 & 1.7 & 4.3 \\
\hline CANUPO 85\% & 0.3 & 0.2 & 10 & 49 & 2.0 & 2.3 & 4.3 \\
\hline CANUPO 90\% & 0.3 & 0.2 & 10 & 49 & 2.1 & 2.1 & 4.2 \\
\hline CANUPO 95\% & 0.3 & 0.2 & 10 & 49 & 2.2 & 2.0 & 4.2 \\
\hline CANUPO 99\% & 0.1 & 0.2 & 10 & 50 & 2.5 & 1.7 & 4.3 \\
\hline
\end{tabular}

We also present the best results for the variants with a lower number of radii than the previous variants (see Table 8). It is evident here that although the number of radii is greatly reduced, and thus the computational effort, the results obtained are still very similar to the best ones.

The above are still the top results in terms of success rates achieved. Table 9 then shows the results obtained with the minimalist filter with only five radii, namely a minimum of $1 \mathrm{~m}$, a step of $1 \mathrm{~m}$ and a maximum of $5 \mathrm{~m}$. Here, the results for probabilities of $85 \%, 90 \%$ and $95 \%$ are quite close to the non-better ones (still better than the geometric filters) but use much less computational power.

The individual filters should also be evaluated in terms of processing time. For the 1457259 point test cloud used, the processing times for the best performing individual methods are PMF: $7.5 \mathrm{~s}$; SMRF: $7.8 \mathrm{~s}$; CSF: $3.9 \mathrm{~s}$; CANUPO $80 \%(0.1 ; 0.1 ; 10 ; 100$ radii): $8 \mathrm{~min} 8 \mathrm{~s}$; CANUPO $80 \%(0.1 ; 0.2 ; 10 ; 50$ radii): 4 min $44 \mathrm{~s}$; CANUPO 
95\% (0.3;0.3;10; 34 radii): 3 min $55 \mathrm{~s}$; CANUPO 95\% (1;1;5; 5 radii): $23.4 \mathrm{~s}$. The computer used was the same in all cases, a laptop with an AMD Ryzen 9 5900HX processor, 32 GB RAM.

Table 8. Best results with radii less than 50 achieved with the Canupo structural filter (Minimum radius - Mi; step between radii - St; Maximum radius - Ma.)

\begin{tabular}{|c|c|c|c|c|c|c|c|}
\hline \multirow[t]{2}{*}{ Filter } & \multicolumn{3}{|c|}{ Parameters } & \multirow{2}{*}{$\begin{array}{c}\text { Radii } \\
\text { number }\end{array}$} & \multicolumn{3}{|c|}{ Results } \\
\hline & $\mathrm{Mi}[\mathrm{m}]$ & St [m] & $\mathrm{Ma}[\mathrm{m}]$ & & E I [\%] & E II [\%] & TE [\%] \\
\hline CANUPO & 0.5 & 0.3 & 5 & 16 & 1.9 & 3.6 & 5.4 \\
\hline CANUPO $75 \%$ & 0.5 & 0.3 & 5 & 16 & 1.9 & 2.7 & 4.6 \\
\hline CANUPO $80 \%$ & 0.5 & 0.3 & 10 & 33 & 2.3 & 2.0 & 4.3 \\
\hline CANUPO $85 \%$ & 0.3 & 0.3 & 10 & 34 & 1.9 & 2.6 & 4.4 \\
\hline CANUPO $90 \%$ & 0.3 & 0.3 & 10 & 34 & 1.9 & 2.4 & 4.3 \\
\hline CANUPO 95\% & 0.3 & 0.3 & 10 & 34 & 2.0 & 2.2 & 4.2 \\
\hline CANUPO 99\% & 0.3 & 0.3 & 10 & 34 & 2.5 & 1.8 & 4.3 \\
\hline
\end{tabular}

Table 9. Results of the Canupo minimalist filter

(Minimum radius - Mi; step between radii - St; Maximum radius - Ma.)

\begin{tabular}{|c|c|c|c|c|c|c|c|}
\hline \multirow[t]{2}{*}{ Filter } & \multicolumn{3}{|c|}{ Parameters } & \multirow{2}{*}{$\begin{array}{c}\text { Radii } \\
\text { number }\end{array}$} & \multicolumn{3}{|c|}{ Results } \\
\hline & $\mathrm{Mi}[\mathrm{m}]$ & St [m] & $\mathrm{Ma}[\mathrm{m}]$ & & E I [\%] & E II [\%] & TE [\%] \\
\hline CANUPO & 1 & 1 & 5 & 5 & 1.2 & 5.3 & 6.5 \\
\hline CANUPO 75\% & 1 & 1 & 5 & 5 & 1.2 & 3.8 & 5.0 \\
\hline CANUPO $80 \%$ & 1 & 1 & 5 & 5 & 3.2 & 2.6 & 5.8 \\
\hline CANUPO $85 \%$ & 1 & 1 & 5 & 5 & 1.3 & 3.4 & 4.7 \\
\hline CANUPO 90\% & 1 & 1 & 5 & 5 & 1.4 & 3.2 & 4.6 \\
\hline CANUPO 95\% & 1 & 1 & 5 & 5 & 1.7 & 2.7 & 4.5 \\
\hline CANUPO 99\% & 1 & 1 & 5 & 5 & 3.2 & 2.6 & 5.8 \\
\hline
\end{tabular}

From the testing performed, it is useful to draw general conclusions that suggest how to choose the filter definition parameters in terms of maximum radius and number of radii. The following graphs partially answer this question. Data from testing the CANUPO filter with a 95\% probability are shown. However, for the other variants, the results are very similar. The data has to be interpreted, taking into account that there are three variables in the system (minimum and maximum radii, radii step or the number of radii), and their influence cannot be separated in the individual filters.

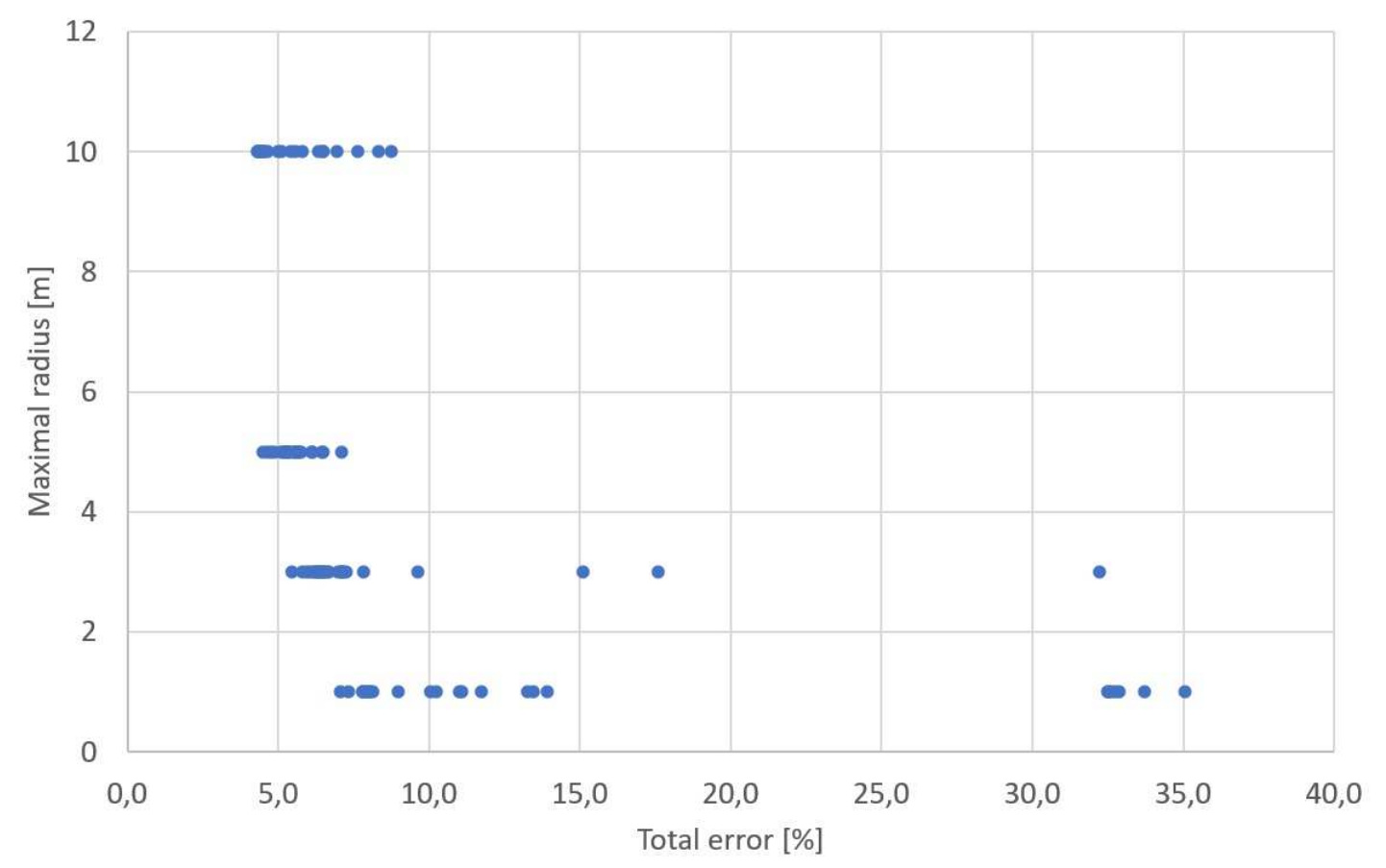




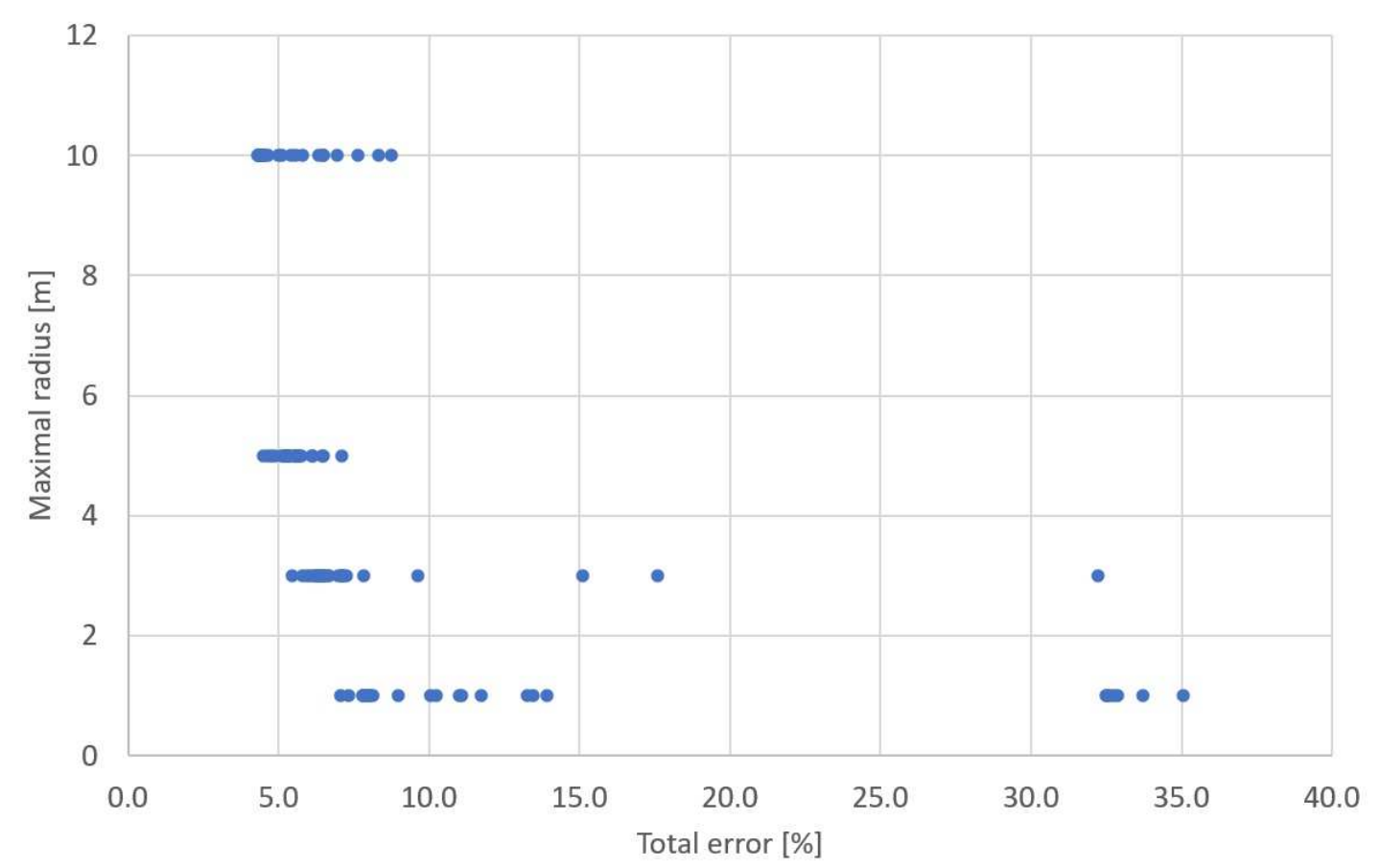

Fig. 6. Size of maximum radius versus total error (CANUPO 95\%)

In Fig. 6, the magnitudes of the maximum radii for each filter are plotted against the total error obtained. The data shows that a larger maximum radius overestimates a smaller total error. Far-right are values exceeding $30 \%$ error; these are filters where only three radii at max are used. This is followed by Fig. 7, which shows the number of radii used as a function of the total error. It is clear that a small number of radii increases the probability that the overall error will be unfavourable.

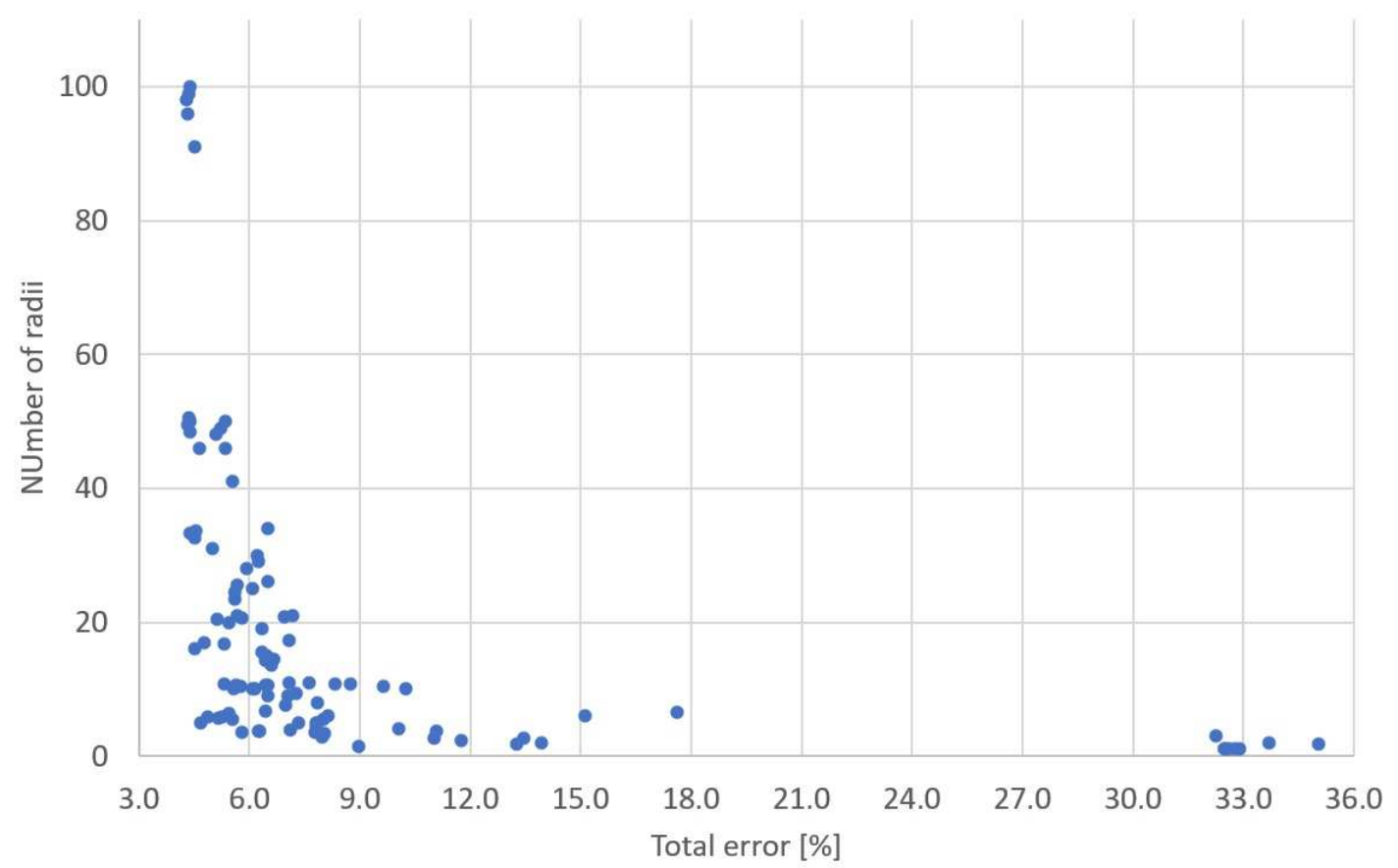

Fig. 7. Number of radii used depending on the total error (CANUPO 95\%)

The results correspond to a logical situation where higher resources spent, with a larger maximum radius and a higher total number of radii used, yields better quality results, but this also increases the computation time. 


\section{Conclusions}

Testing of ground filtering procedures on real data corresponding to the nature of the mining area was performed. The tested geometric filters CSF, PMF and SMRF showed an overall error of about $7.5 \%$ in the best case, of which error type I constitutes a significantly larger part (about 6\%) than error type II (about 2\%). In contrast, the tested CANUPO structural filter in basic use achieved up to $5.2 \%$ total error, using a defined probability bound of up to $4.1 \%$. The distribution of errors of type I and type II is almost even here. The specific probability set here has a relatively small effect on the result, at $0.1 \%$ of the total error.

The nature of the operation of geometric and structural filters is different; geometric filters practically approximate the terrain by a surface and consider as points to be removed those points that are further from the surface than the threshold. Because this surface is relatively coarse compared to the resolution of the filtered cloud itself, the threshold must be set relatively large (cloud resolution of about $0.1 \mathrm{~m}$, a suitable threshold for the test data was, for instance, $0.3 \mathrm{~m}$ for CSF). Thus, all points will remain in this space, even those that, for example, represent low vegetation. Therefore, the bulk of the total error here is made up of the first kind of error - i.e., points that were not removed in error. Terrain points are considered to be those that are lowest, without consideration of their nature.

In contrast, the CANUPO-based structure filter classifies points based on their neighbourhood (multiple neighbourhoods with different radii) and thus removes all points that have a noise character (or do not match the character of the surface), regardless of their location. Thus, it can be advantageously applied to such data where rugged surfaces (even with a large slope) are present. For these reasons, the structure filter does not make errors on rugged surfaces, as can be seen in the test data on the heap in the middle of the area. In terms of the design of the CANUPO classifier, based on the experiment, it can be concluded that the quality of the result is not fundamentally dependent on the number and interval of parameters. However, a higher number of radii used and a larger maximum radius increases the probability of a good quality result. When designing filters, it is advisable to consider the resolution of the cloud versus the size of the radius and not to take the reported radii as absolute numbers.

\section{References}

Blistan, P., Jacko, S., Kovanič, L., Kondela, J., Pukanská, K. and Bartoš, K. (2020) TLS and SfM Approach for Bulk Density Determination of Excavated Heterogeneous Raw Materials, Minerals, 10(2), p. 174. doi: 10.3390/min10020174.

Blišt'an, P., Kovanič, L', Urban, R., Štroner, M., and Homolová, Z. (2020). Verification of UAS photogrammetry approach for mass movement monitoring in alpine terrain: a case study in High Tatras, Slovakia. In Eighth International Conference on Remote Sensing and Geoinformation of the Environment (RSCy2020) (Vol. 11524, p. 115241Y). International Society for Optics and Photonics. doi.org/10.1117/12.2571169

Brodu, N. and Lague, D. (2012) 3D terrestrial lidar data classification of complex natural scenes using a multiscale dimensionality criterion: Applications in geomorphology, ISPRS Journal of Photogrammetry and Remote Sensing, 68, pp. 121-134. doi: 10.1016/j.isprsjprs.2012.01.006.

Cai, S., Zhang, W., Liang, X., Wan, P., Qi, J., Yu, S., Yan, G. and Shao, J. (2019) Filtering Airborne LiDAR Data Through Complementary Cloth Simulation and Progressive TIN Densification Filters, Remote Sensing, 11(9), p. 1037. doi: 10.3390/rs11091037.

Dihkan, M. and Mus, E. (2021) Automatic detection of power transmission lines and risky object locations using UAV LiDAR data, Arabian Journal of Geosciences, 14(7). doi: 10.1007/s12517-021-06947-1.

Feroz, S. and Abu Dabous, S. (2021) UAV-Based Remote Sensing Applications for Bridge Condition Assessment, Remote Sensing, 13(9), p. 1809. doi: 10.3390/rs13091809.

Hu, T., Sun, X., Su, Y., Guan, H., Sun, Q., Kelly, M. and Guo, Q. (2020) Development and Performance Evaluation of a Very Low-Cost UAV-Lidar System for Forestry Applications, Remote Sensing, 13(1), p. 77. doi: 10.3390/rs13010077.

Cheng, D., Zhao, D., Zhang, J., Wei, C. and Tian, D. (2021) PCA-Based Denoising Algorithm for Outdoor Lidar Point Cloud Data, Sensors, 21(11), p. 3703. doi: 10.3390/s21113703.

Jaud, M., Bertin, S., Beauverger, M., Augereau, E. and Delacourt, C. (2020) RTK GNSS-Assisted Terrestrial SfM Photogrammetry without GCP: Application to Coastal Morphodynamics Monitoring, Remote Sensing, 12(11), p. 1889. doi: 10.3390/rs12111889.

Jon, J., Koska, B. and Pospíšil, J. (2013) AUTONOMOUS AIRSHIP EQUIPPED BY MULTI-SENSOR MAPPING PLATFORM, The International Archives of the Photogrammetry, Remote Sensing and Spatial Information Sciences, XL-5/W1, pp. 119-124. doi: 10.5194/isprsarchives-xl-5-w1-119-2013. 
Keqi Zhang, Shu-Ching Chen, Whitman, D., Mei-Ling Shyu, Jianhua Yan and Chengcui Zhang (2003) A progressive morphological filter for removing nonground measurements from airborne LIDAR data, IEEE Transactions on Geoscience and Remote Sensing, 41(4), pp. 872-882. doi: 10.1109/tgrs.2003.810682.

Klápště, P., Fogl, M., Barták, V., Gdulová, K., Urban, R. and Moudrý, V. (2020) Sensitivity analysis of parameters and contrasting performance of ground filtering algorithms with UAV photogrammetry-based and LiDAR point clouds, International Journal of Digital Earth, 13(12), pp. 1672-1694. doi: 10.1080/17538947.2020.1791267.

Klouček, T., Komárek, J., Surový, P., Hrach, K., Janata, P. and Vašíček, B. (2019) The Use of UAV Mounted Sensors for Precise Detection of Bark Beetle Infestation, Remote Sensing, 11(13), p. 1561. doi: 10.3390/rs11131561.

Komárek, J., Klouček, T. and Prošek, J. (2018) The potential of Unmanned Aerial Systems: A tool towards precision classification of hard-to-distinguish vegetation types?, International Journal of Applied Earth Observation and Geoinformation, 71, pp. 9-19. doi: 10.1016/j.jag.2018.05.003.

Koska, B. and Křemen, T. (2013) The combination of laser scanning and structure from motion technology for creation of accurate exterior and interior orthophotos of st. Nicholas baroque church, The International Archives of the Photogrammetry, Remote Sensing and Spatial Information Sciences, XL-5/W1, pp. 133138. doi: 10.5194/isprsarchives-xl-5-w1-133-2013.

Koska, B., Jirka, V., Urban, R., Křemen, T., Hesslerová, P., Jon, J., Pospíšil, J. and Fogl, M. (2017) Suitability, characteristics, and comparison of an airship UAV with lidar for middle size area mapping, International Journal of Remote Sensing, 38(8-10), pp. 2973-2990. doi: 10.1080/01431161.2017.1285086.

Kovanič, L. (2013) Possibilities of terrestrial laser scanning method in monitoring of shape deformation in mining plants. Inżynieria Miner. J. Pol. Miner. Eng. Soc. 2013, 31, 29-41.

Kovanič, L., Ambriško, L., Marasová, D., Blišt’an, P., Kasanický, T. and Cehlár, M. (2021) Long-Exposure RGB Photography with a Fixed Stand for the Measurement of a Trajectory of a Dynamic Impact Device in Real Scale, Sensors, 21(20), p. 6818. doi: 10.3390/s21206818.

Kovanič, L., Blistan, P., Štroner, M., Urban, R. and Blistanova, M. (2021) Suitability of Aerial Photogrammetry for Dump Documentation and Volume Determination in Large Areas, Applied Sciences, 11(14), p. 6564. doi: 10.3390/app11146564.

Kovanič, L., Blistan, P., Urban, R., Štroner, M., Blišt’anová, M., Bartoš, K. and Pukanská, K. (2020) Analysis of the Suitability of High-Resolution DEM Obtained Using ALS and UAS (SfM) for the Identification of Changes and Monitoring the Development of Selected Geohazards in the Alpine Environment-A Case Study in High Tatras, Slovakia, Remote Sensing, 12(23), p. 3901. doi: 10.3390/rs12233901.

Kovanič, L', Blistan, P., Urban, R., Štroner, M., Pukanská, K., Bartoš, K. and Palková, J. (2020) Analytical Determination of Geometric Parameters of the Rotary Kiln by Novel Approach of TLS Point Cloud Segmentation, Applied Sciences, 10(21), p. 7652. doi: 10.3390/app10217652.

Křemen, T. (2020) Measurement and Documentation of St. Spirit Church in Liběchov. In Advances and Trends in Geodesy, Cartography and Geoinformatics II; Taylor \& Francis Group: London, UK, 2020; pp. 44-49. ISBN 978-0-367-34651-5. doi:10.1201/9780429327025.

Kumar, B., Yadav, M., Lohani, B. and Singh, A. (2018) A two-stage algorithm for ground filtering of airborne laser scanning data, International Journal of Remote Sensing, 39(20), pp. 6757-6783. doi: 10.1080/01431161.2018.1466074.

Li, Y., Wang, J., Li, B., Sun, W. and Li, Y. (2020) An adaptive filtering algorithm of multilevel resolution point cloud, Survey Review, pp. 1-12. doi: 10.1080/00396265.2020.1755163.

Lin, Y., Cheng, Y., Zhou, T., Ravi, R., Hasheminasab, S., Flatt, J., Troy, C. and Habib, A. (2019) Evaluation of UAV LiDAR for Mapping Coastal Environments, Remote Sensing, 11(24), p. 2893. doi: $10.3390 / \mathrm{rs} 11242893$.

Meng, X., Wang, L., Silván-Cárdenas, J. and Currit, N. (2009) A multi-directional ground filtering algorithm for airborne LIDAR, ISPRS Journal of Photogrammetry and Remote Sensing, 64(1), pp. 117-124. doi: 10.1016/j.isprsjprs.2008.09.001.

Montealegre, A., Lamelas, M. and de la Riva, J. (2015) A Comparison of Open-Source LiDAR Filtering Algorithms in a Mediterranean Forest Environment, IEEE Journal of Selected Topics in Applied Earth Observations and Remote Sensing, 8(8), pp. 4072-4085. doi: 10.1109/jstars.2015.2436974.

Moudrý, V., Klápště, P., Fogl, M., Gdulová, K., Barták, V. and Urban, R. (2020) Assessment of LiDAR ground filtering algorithms for determining ground surface of non-natural terrain overgrown with forest and steppe vegetation, Measurement, 150, p. 107047. doi: 10.1016/j.measurement.2019.107047.

Moudrý, V., Urban, R., Štroner, M., Komárek, J., Brouček, J. and Prošek, J. (2018) Comparison of a commercial and home-assembled fixed-wing UAV for terrain mapping of a post-mining site under leaf-off conditions, International Journal of Remote Sensing, 40(2), pp. 555-572. doi: 10.1080/01431161.2018.1516311. 
Pingel, T., Clarke, K. and McBride, W. (2013) An improved simple morphological filter for the terrain classification of airborne LIDAR data, ISPRS Journal of Photogrammetry and Remote Sensing, 77, pp. 2130. doi: 10.1016/j.isprsjprs.2012.12.002.

Polat, N. and Uysal, M. (2015) Investigating performance of Airborne LiDAR data filtering algorithms for DTM generation, Measurement, 63, pp. 61-68. doi: 10.1016/j.measurement.2014.12.017.

Pukanská, K., Bartoš, K., Bella, P., Gašinec, J., Blistan, P. and Kovanič, L'. (2020) Surveying and High-Resolution Topography of the Ochtiná Aragonite Cave Based on TLS and Digital Photogrammetry, Applied Sciences, 10(13), p. 4633. doi: 10.3390/app10134633.

Rashidi, P. and Rastiveis, H. (2017) Ground filtering lidar data based on multi-scale analysis of height difference threshold, The International Archives of the Photogrammetry, Remote Sensing and Spatial Information Sciences, XLII-4/W4, pp. 225-229. doi: 10.5194/isprs-archives-xlii-4-w4-225-2017.

Ren, H., Zhao, Y., Xiao, W. and Hu, Z. (2019) A review of UAV monitoring in mining areas: current status and future perspectives, International Journal of Coal Science \& Technology, 6(3), pp. 320-333. doi: 10.1007/s40789-019-00264-5.

Serifoglu Yilmaz, C., Yilmaz, V. and Güngör, O. (2018) Investigating the performances of commercial and noncommercial software for ground filtering of UAV-based point clouds, International Journal of Remote Sensing, 39(15-16), pp. 5016-5042. doi: 10.1080/01431161.2017.1420942.

Shaw, L., Helmholz, P., Belton, D. and Addy, N. (2019) COMPARISON OF UAV LIDAR AND IMAGERY FOR BEACH MONITORING, The International Archives of the Photogrammetry, Remote Sensing and Spatial Information Sciences, XLII-2/W13, pp. 589-596. doi: 10.5194/isprs-archives-xlii-2-w13-589-2019.

Shi, X., Ma, H., Chen, Y., Zhang, L. and Zhou, W. (2018) A parameter-free progressive TIN densification filtering algorithm for lidar point clouds, International Journal of Remote Sensing, 39(20), pp. 6969-6982. doi: 10.1080/01431161.2018.1468109.

Silva, C., Klauberg, C., Hentz, Â., Corte, A., Ribeiro, U. and Liesenberg, V. (2018) Comparing the Performance of Ground Filtering Algorithms for Terrain Modeling in a Forest Environment Using Airborne LiDAR Data, Floresta e Ambiente, 25(2). doi: 10.1590/2179-8087.015016.

Siwiec, J. (2018) Comparison of Airborne Laser Scanning of Low and High Above Ground Level for Selected Infrastructure Objects, Journal of Applied Engineering Sciences, 8(2), pp. 89-96. doi: 10.2478/jaes-20180023.

Susaki, J. (2012) Adaptive Slope Filtering of Airborne LiDAR Data in Urban Areas for Digital Terrain Model (DTM) Generation, Remote Sensing, 4(6), pp. 1804-1819. doi: 10.3390/rs4061804.

Šedina, J., Hůlková, M., Pavelka, K. and Pavelka, jr, K. (2018) RPAS for documentation of Nazca aqueducts, European Journal of Remote Sensing, 52(sup1), pp. 174-181. doi: 10.1080/22797254.2018.1537684.

Štroner, M., Urban, R. and Línková, L. (2021) A New Method for UAV Lidar Precision Testing Used for the Evaluation of an Affordable DJI ZENMUSE L1 Scanner, Remote Sensing, 13(23), p. 4811. doi: $10.3390 / \mathrm{rs} 13234811$.

Štroner, M., Urban, R., Lidmila, M., Kolář, V. and Křemen, T. (2021) Vegetation Filtering of a Steep Rugged Terrain: The Performance of Standard Algorithms and a Newly Proposed Workflow on an Example of a Railway Ledge, Remote Sensing, 13(15), p. 3050. doi: 10.3390/rs13153050.

Štroner, M., Urban, R., Reindl, T., Seidl, J. and Brouček, J. (2020) Evaluation of the Georeferencing Accuracy of a Photogrammetric Model Using a Quadrocopter with Onboard GNSS RTK, Sensors, 20(8), p. 2318. doi: $10.3390 / \mathrm{s} 20082318$.

Štroner, M., Urban, R., Seidl, J., Reindl, T. and Brouček, J. (2021) Photogrammetry Using UAV-Mounted GNSS RTK: Georeferencing Strategies without GCPs, Remote Sensing, 13(7), p. 1336. doi: 10.3390/rs13071336.

Štroner, M.; Křemen, T.; Braun, J.; Urban, R.; Blistan, P. and Kovanič, L. (2019) Comparison of 2.5d volume calculation methods and software solutions using point clouds scanned before and after mining. Acta Montan. Slovaca 2019, 24, 296-306.

Tan, J., Zhao, H., Yang, R., Liu, H., Li, S. and Liu, J. (2021) An Entropy-Weighting Method for Efficient PowerLine Feature Evaluation and Extraction from LiDAR Point Clouds, Remote Sensing, 13(17), p. 3446. doi: $10.3390 / \mathrm{rs} 13173446$.

Teppati Losè, L., Chiabrando, F. and Giulio Tonolo, F. (2020) Boosting the Timeliness of UAV Large Scale Mapping. Direct Georeferencing Approaches: Operational Strategies and Best Practices, ISPRS International Journal of Geo-Information, 9(10), p. 578. doi: 10.3390/ijgi9100578.

Tinkham, W., Huang, H., Smith, A., Shrestha, R., Falkowski, M., Hudak, A., Link, T., Glenn, N. and Marks, D. (2011) A Comparison of Two Open Source LiDAR Surface Classification Algorithms, Remote Sensing, 3(3), pp. 638-649. doi: 10.3390/rs3030638.

Torresan, C., Berton, A., Carotenuto, F., Chiavetta, U., Miglietta, F., Zaldei, A. and Gioli, B. (2018) Development and Performance Assessment of a Low-Cost UAV Laser Scanner System (LasUAV), Remote Sensing, 10(7), p. 1094. doi: 10.3390/rs10071094. 
Urban, R., Štroner, M., Blistan, P., Kovanič, L., Patera, M., Jacko, S., Duuriška, I., Kelemen, M. and Szabo, S. (2019) The Suitability of UAS for Mass Movement Monitoring Caused by Torrential Rainfall—A Study on the Talus Cones in the Alpine Terrain in High Tatras, Slovakia, ISPRS International Journal of GeoInformation, 8(8), p. 317. doi: 10.3390/ijgi8080317.

Urban, R.; Koska, B.; Moudry, V. and Solsky, M. (2016) Terrain of post mining site from airship lidar. In Proceedings of the 16th International Multidisciplinary Scientific GeoConference, SGEM2016, Albena, Bulgaria, 30 June-6 July 2016; Volume 2, pp. 577-584.

Urban, R.; Štroner, M. nad Kuric, I. (2020).The use of onboard UAV GNSS navigation data for area and volume calculation (2020) Acta Montanistica Slovaca, 25, pp. 361-374. doi: 10.46544/ams.v25i3.9.

Urban, R.; Štroner, M.; Křemen, T.; Braun, J. and Moeser, M. (2018) A novel approach to estimate systematic and random error of terrain derived from UAV s: A case study from a post-mining site. Acta Montan. Slovaca 2018, 23, 325-336.

Vacca, G., Dessì, A. and Sacco, A. (2017) The Use of Nadir and Oblique UAV Images for Building Knowledge, ISPRS International Journal of Geo-Information, 6(12), p. 393. doi: 10.3390/ijgi6120393.

Wei, L., Yang, B., Jiang, J., Cao, G. and Wu, M. (2016) Vegetation filtering algorithm for UAV-borne lidar point clouds: a case study in the middle-lower Yangtze River riparian zone, International Journal of Remote Sensing, 38(8-10), pp. 2991-3002. doi: 10.1080/01431161.2016.1252476.

Zhang, W., Qi, J., Wan, P., Wang, H., Xie, D., Wang, X. and Yan, G. (2016) An Easy-to-Use Airborne LiDAR Data Filtering Method Based on Cloth Simulation, Remote Sensing, 8(6), p. 501. doi: 10.3390/rs8060501.

Žabota, B. and Kobal, M. (2021) Accuracy Assessment of UAV-Photogrammetric-Derived Products Using PPK and GCPs in Challenging Terrains: In Search of Optimized Rockfall Mapping, Remote Sensing, 13(19), p. 3812. doi: 10.3390/rs13193812. 